\title{
Industrial potential of Bacaba (Oenocarpus bacaba) in powder: antioxidant activity, spectroscopic and morphological behavior
}

\author{
Orquídea Vasconcelos dos SANTOS ${ }^{1 *}$ (i), Arliane Amaral VIANA ${ }^{1}$, Stephanie Dias SOARES ${ }^{2}$, \\ Evelyn Lais Santos VIEIRA ${ }^{1}$, Mayara Galvão MARTINS², Francisco das Chagas Alves do NASCIMENTO ${ }^{1}$, \\ Barbara Elisabeth TEIXEIRA-COSTA ${ }^{3}$
}

\begin{abstract}
The objective of this research was to analyze the industrial potential of a bacaba powder (Oenocarpus bacaba) obtained by different drying methods, evaluating antioxidant activity, spectroscopic and morphological behavior and addition to the composition of inorganic elements. The content of anthocyanins, flavonoids and carotenoids of each powder were determined as well as the total phenolic compounds. The structure of the granules of the powder were visualized via scanning electron microscopy (SEM) and the elemental composition was attained by the X-ray spectroscopic energy dispersive system (EDS). The data suggest that the freeze-drying method is more efficient in obtaining the bacaba powder material. The increase in temperature applied in the convection drying process caused a reduction in the bioactive compound content and elements with antioxidant activity, it severely damaged the morphology of the plant membrane and influenced the composition of the spectral bands. Thus, this study indicates that the freezer-drying method could be particularly useful for obtaining bacaba powder in off-season periods, and that bacaba itself is a raw material that could be exploited by several industrial segments.
\end{abstract}

Keywords: drying; off-season; powder; processing.

Practical Application: Research with new ingredients applicable to different industrial segments promotes the search for new products and by-products derived from unconventional fruits from the amazon region, such as bacaba (Oenocarpus bacaba). This power as high bioactives content and functional terms which is active in the prevention of cardiovascular diseases, coupled with a high thermal and oxidative stability, with potential for application in several industrial segments.

\section{Introduction}

The great Amazonian biodiversity has been the focus of vast researches in favor of the development, improvement and design of agrotechnological products. Natural products obtained from Amazon plants have potential application in several industrial sectors including pharmaceuticals, chemicals, dermocosmetics, oleochemicals and biofuels. In this context, the bacaba (Oenocarpus bacaba), a tree belonging to the Arecacea botanical family, emerges as a prospective market option, with the long and productive harvest extending from April to December being a particularly attractive feature. The bacaba fruit has a high content of lipids, reduced content of sugars and proteins, and is a source of bioactive compounds, pigments and natural antioxidants. The consumption of this fruit is predominantly in the form of a drink, which is produced and consumed similarly to that of açaí (Euterpe oleracea Mart.), with these fruits competing commercially due to their off-season (Finco et al., 2016; Lauvai et al., 2017; Pinto et al., 2018; Nascimento et al., 2019).

The different genotypes of bacaba have been the focus of research, particularly in the evaluation of antioxidant activity and phenolic compounds, in natura, as in the research of Carvalho et al. (2016) and Brabo de Sousa et al. (2018), as well as the investigation of extracts in the induction of apoptosis and cell adipogenesis as a novel cancer treatment (Finco et al., 2016; Lauvai et al., 2017). In the industrial segment, studies have concentrated on the isolation of its energy constituents, lipid content and residual oils using gases in a supercritical state (Pinto et al., 2018; Nascimento et al., 2019).

Studies investigating the bacaba fruit have emphasized the fresh state, and/or the isolation of its products and byproducts. However, research in general has not directed efforts to maximizing the isolation of high-quality products to meet the demand still required when the fruit is in the off-season. In this sense, the economic potential of this fruit could be augmented if technologies are applied that increase its stability and reduce its humidity, especially in the edaphoclimatic conditions typical of the growing region, thereby improving its commercialization to different parts of the world, as occurs with açaí (Pinto et al., 2018; Nascimento et al., 2019).

To this end, alternative methods, such as the application of convective drying technology, could be employed as one of the ways to offer the product in-between seasons. This 
method stands out for the feasibility and simplicity of the process, which thus affects the cost and benefit (Morais et al., 2019). The freeze-drying process is another promising method in drying food (Costa et al., 2019), as its operation is based on the sublimation process with high pressures and low temperature. Due to the specific conditions of each method, the product must be evaluated in terms of possible changes in bioactivity, spectroscopic composition and morphological structures after the application of each drying method.

Given this context, this research aimed to evaluate the industrial potential of bacaba (Oenocarpus bacaba) in powder obtained by the convective and lyophilized methods, assessing antioxidant, spectroscopic and morphological changes, in order to present this raw material as an alternative for the most diverse industrial segments.

\section{Material and methods}

\subsection{Raw material and sample preparation}

In order to carry out the present research, about $5 \mathrm{~kg}$ of the bacaba pulp (Oenocarpus bacaba) was obtained from the market in the city of Belém, Pará, Brazil. The samples were transported in plastic bags of low-density polyethylene (LDPE) and stored at a temperature of $20^{\circ} \mathrm{C}$ until use in the Food Science Laboratory at the Faculty of Nutrition (FANUT), Federal University of Pará (UFPA).

Samples were first washed and dried then processed by either the lyophilized or convective methods to obtain the bacaba powder, LB or CB respectively. For the LB powder, freeze-drying in a lyophilizer, model Liotop SL-404, was carried out for $48 \mathrm{~h}$ followed by milling in a Reffinox miller, model Willye TE-650, (Tecnal, São Paulo, Brazil). Subsequently, a solid-liquid extraction was carried out in Soxhlet apparatus to obtain the oil (Association of Official Analytical Chemists, 2000). The oil extraction and other analyses were performed in triplicate.

For the $\mathrm{CB}$ powder, the convective drying process was carried out in a greenhouse with air circulation (Tronh brand, model 170) at $60^{\circ} \mathrm{C}$ (Morais et al., 2019). The pulp was placed on a tray, in order to allow perpendicular air flow and simulate the thin-layer drying process. The dry sample was then ground in a knife mill (Willye, TE-650).

\subsection{Analyses of bioactive compounds}

\section{Extract preparation}

Dried and pulverized LB and CB samples were then extracted with a $70 \%(\mathrm{w} / \mathrm{v})$ ethanol solution in water according to the percolation process. To obtain the crude extracts (CE), the resulting solution was concentrated in a rotary evaporator, model Laborota 4000 (Heidolph, Schwabach, Germany), under low pressure and controlled temperature $\left(40 \pm 5^{\circ} \mathrm{C}\right)$.

\section{Total polyphenol content}

The polyphenol content of the CEs was analyzed according to the Folin-Ciocalteu assay, as reported by Aliakbarian et al. (2011), using an UV-Vis spectrophotometer (model UV-1800, Shimadzu, Tokyo, Japan) at $725 \mathrm{~nm}$ wavelength. The results were calculated based on a gallic acid standard curve using the following regression equation $y=0.0017 x\left(R^{2}=0.9966\right)$.

\section{Flavonoid content}

The flavonoid content of the CEs was analyzed following the assay reported by Francis (1982), using an UV-Vis spectrophotometer (model UV-1800, Shimadzu, Tokyo, Japan) at $374 \mathrm{~nm}$ wavelength.

\subsection{Antioxidant activity - DPPH and ABTS method}

The antioxidant activity of CEs was determined according to either the assay of 2,2-diphenyl picrylhydrazyl radical (DPPH) inhibition or to 2,2'-azino-bis (3-ethylbenzothiazoline) 6-sulfonic acid radical cation $\left(\mathrm{ABTS}^{+}\right)$. To determine the antioxidant activity according to the DPPH method, $75 \mu \mathrm{L}$ CE aliquots were first diluted (1:150) and mixed with $2,925 \mu \mathrm{L}$ of a $25.0 \mathrm{mg} \mathrm{L}^{-1} \mathrm{DPPH}$ methanolic solution, which was also used as a blank (Tepe et al., 2007). The mixture was then kept in the dark at room temperature for $30 \mathrm{~min}$, and the absorbance read at $515 \mathrm{~nm}$ on a UV/Vis spectrophotometer. The ability to capture the DPPH radical was expressed as yield of scavenging $\left(\mathrm{Y}_{\mathrm{Sc}}\right)$ according to Equation 1:

$Y_{S c}(\%)=\frac{A_{b}-A_{s}}{A_{b}} \times 100$

where $A_{b}$ is the absorbance of the blank (DPPH) at the start and $\mathrm{A}_{\mathrm{s}}$ is the absorbance of the sample (DPPH plus the CE) after $30 \mathrm{~min}$.

The antioxidant activity was finally expressed as concentration of 6-hydroxy-2,5,7,8-tetramethylchroman-2-carboxylic acid (Trolox), taken as a reference antioxidant, through a calibration curve $(y=0.0774 x-0.0611)$ correlating the percentage inhibition (y) with Trolox concentration (x). The value of IC50 was defined as the final concentration, expressed in $\mathrm{mg} \mathrm{mL}^{-1}$ of the $\mathrm{CE}$, able to reduce the initial DPPH concentration by $50 \%$.

The antioxidant activity of the CEs was also determined according to the ABTS method (Re et al., 1999), with some modifications. For this purpose, $50 \mu \mathrm{L} \mathrm{CE}$ aliquots were diluted and added to $1.0 \mathrm{~mL}$ of $\mathrm{ABTS}^{+}$solution, and the absorbance of samples was read at $734 \mathrm{~nm}$ after $2 \mathrm{~min}$ of reaction. Antioxidant activity was calculated using a standard Trolox curve expressed in $\mu \mathrm{g} \mathrm{L}^{-1}$. The results were expressed in $\mathrm{mg}$ of Trolox equivalent antioxidant capacity per $100 \mathrm{~g}$ of crude extract (mgTEAC $100 \mathrm{~g}^{-1} \mathrm{CE}$ ).

\subsection{Infrared spectroscopy (FTIR)}

Fourier transform infrared spectroscopy (FTIR) analyses were carried out using a Perkin Elmer spectrometer, model Frontier 98737 (Waltham, MA, USA) at $25^{\circ} \mathrm{C}$ in the $4000-400 \mathrm{~cm}^{-1}$ wavenumber range. The sample spectra were registered by 
averaging 20 scans with a resolution of $4 \mathrm{~cm}^{-1}$ in transmission mode.

\subsection{Morphological analysis by scanning electron microscopy}

The degreased samples of bacaba were deposited on a sample holder with the aid of carbon tape and metallized with $\mathrm{Au} / \mathrm{Pd}$ using a metallizer, model SC7620 (Quorum Technologies, Lewes, UK). Metallization was performed for $2 \mathrm{~min}$ with $5 \mathrm{~mA}$ current. Electromicrographs were obtained using a scanning electron microscope, model VEGA 3 (Tescan, Cranberry Township, PA, USA), with an electron beam current of $85-90 \mu \mathrm{A}$ and an acceleration voltage of $10.0 \mathrm{kV}$. The micrometric scales were designed in the same optical conditions. The analysis of elementary minerals was carried out in the same equipment with a coupled energy dispersive X-ray spectrometer (EDS) system, installed at the Nanomanipulation Laboratory (PPGF/UFPA).

\subsection{Statistical analysis}

The results of the evaluation of the bioactive compounds of the dry products were subjected to analysis of variance (ANOVA) and Tukey's complementary test, for comparison of means, using the Statistica ${ }^{\oplus}$ version 7.0 program (StatSoft, 2000).

\section{Results and discussion}

The results of bioactive compounds and antioxidant activity of bacaba pulp powders obtained by both the lyophilized (LB) and convective (CB) drying methods are given in Table 1 . The highest values were found in the freeze-dried bacaba powder (LB). The analysis of variance (ANOVA) indicated a significant difference $(p \leq 0.05)$ between the means for the different products.

The polyphenol content found, regardless of the drying process used, was lower than the reported average value of açaí

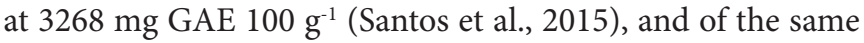
order of magnitude or higher than other species of bacaba (Oenocarpus distichus Mart.) (81.86 to $363.01 \mathrm{mg} \mathrm{GAE} 100 \mathrm{~g}^{-1}$ $\mathrm{db})$ and for other fruits native to the Amazon region, such as inajá (109.75 mg GAE $100 \mathrm{~g}^{-1}$ ), tucumã (127.27 mg GAE $100 \mathrm{~g}^{-1}$ ) (Santos et al., 2015), bacuri (521 mg GAE $100 \mathrm{~g}^{-1}$ ), cupuaçu (305 mg GAE $100 \mathrm{~g}^{-1}$ ) and abiu (430 mg GAE $100 \mathrm{~g}^{-1}$ ) (Becker et al., 2018). Like flavonoids and anthocyanins, polyphenols help as antioxidants by reducing the action of free radicals, as well as acting in other systems as supporting elements in the prevention of human health problems (Finco et al., 2016; Lauvai et al., 2017; Nascimento et al., 2019).
The levels of flavonoids found were higher than bacaba and its multiple genotypes (9.53 to $38.19 \mathrm{mg} 100 \mathrm{~g}^{-1}$ ) (Brabo de Sousa et al., 2018), inajá (34.14 $\mathrm{mg} 100 \mathrm{~g}^{-1}$ ) and pupunha $\left(48.57 \mathrm{mg} 100 \mathrm{~g} \mathrm{~g}^{-1}\right)$, and similar to that obtained for lyophilized bacaba of the same species $\left(62.02 \mathrm{mg} 100 \mathrm{~g}^{-1}\right.$ ) reported by Santos et al. (2015).

Anthocyanins, on the other hand, presented averages of 21.32

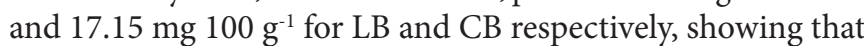
the temperature affects the conformation of the flavylium cation, destabilizing the sugar molecules present in the anthocyanin structures, thereby resulting in the generation of degradation compounds, rupture of double bonds, cleavage of $\mathrm{B}$ and $\mathrm{C}$ rings of the basic chemical structures of anthocyanins, inducing chemical and sensory modifications (Méndez-Lagunas et al., 2017). Carvalho et al. (2016) obtained similar results for bacaba,

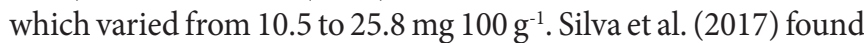
higher values in the fruits of bacabi $\left(40.31 \mathrm{mg} 100 \mathrm{~g}^{-1}\right)$ and açaí (73.54 mg $100 \mathrm{~g}^{-1}$ ), which belong to the same botanical family as bacaba. Anthocyanins, in addition to being responsible for the $\mathrm{red} /$ purple coloration of many fruits, are potentially beneficial to health due to their antioxidant activity and anticarcinogenic power (Méndez-Lagunas et al., 2017).

The levels of total carotenoids expressed in $\beta$-carotene were, on average, 1068.3 and $908.17 \mu \mathrm{g} 100 \mathrm{~g}^{-1}$ for LB and CB respectively. The reduction in the value for the form obtained by convective drying is a result of the carotenoid thermosensitivity. Santos et al. (2015) evaluated fresh bacaba fruit and found a value $\geq 700 \mu \mathrm{g} 100 \mathrm{~g}^{-1}$ and reported lower levels of carotenoids from other Amazonian fruit sources, such as inajá (400 $\left.\mu \mathrm{g} 100 \mathrm{~g}^{-1}\right)$, bacuri (100 $\left.\mu \mathrm{g} 100 \mathrm{~g}^{-1}\right)$ and pequia $\left(400 \mu \mathrm{g} 100 \mathrm{~g}^{-1}\right)$.

In contrast, higher values of total carotenoids were found in other species of Amazonian fruits typically considered high content sources of carotenoids, such as tucumã $\left(8390 \mu \mathrm{g} 100 \mathrm{~g}^{-1}\right)$,

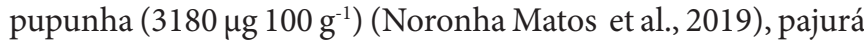

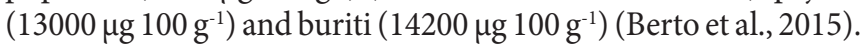

Britton and Khachik (2009) classify the carotenoid content of foods as: low $\left(0-100 \mu \mathrm{g} 100 \mathrm{~g}^{-1}\right)$, moderate $\left(100-500 \mu \mathrm{g} 100 \mathrm{~g}^{-1}\right)$, high (500-2000 $\left.\mu \mathrm{g} 100 \mathrm{~g}^{-1}\right)$ and very high $\left(\geq 2000 \mu \mathrm{g} 100 \mathrm{~g}^{-1}\right)$. Based on this classification, $\mathrm{LB}$ and $\mathrm{CB}$ can be characterized as foods with a high concentration of carotenoids.

Regarding the antioxidant capacity of bacaba powders, the results indicate both were efficient in sequestering the ABTS radical, with averages of 75.5 and $63.45 \mu \mathrm{mol}$ Trolox $\mathrm{g}^{-1}$ for LB and $\mathrm{CB}$ respectively. Similar results were found by Brabo de

Table 1. Bioactive compounds and antioxidant capacity.

\begin{tabular}{|c|c|c|}
\hline Bioactive substances & LB & $\mathrm{CB}$ \\
\hline Total polyphenols (mg GAE $100 \mathrm{~g}^{-1}$ ) & $290.93 b \pm 7.35$ & $1118.11 \mathrm{a} \pm 5.35$ \\
\hline Flavonoids (mg $100 \mathrm{~g}^{-1}$ ) & $54.25 \mathrm{a} \pm 1.18$ & $43.35 b \pm 3.47$ \\
\hline Anthocyanins (mg $100 \mathrm{~g}^{-1}$ ) & $21.32 \mathrm{a} \pm 1.50$ & $17.15 b \pm 4.23$ \\
\hline Carotenoids (mg $100 \mathrm{~g}^{-1}$ ) & $1068.30 \mathrm{a} \pm 10.50$ & $908.17 b \pm 5.75$ \\
\hline ABTS $\left(\mu \mathrm{mol}\right.$ Trolox $\left.\mathrm{g}^{-1}\right)$ & $75.50 \mathrm{a} \pm 5.50$ & $63.45 \mathrm{~b} \pm 4.35$ \\
\hline $\mathrm{DPPH}\left(\mathrm{g} \mathrm{g}^{-1}\right)$ & $1550.10 \mathrm{a} \pm 15.50$ & $1757.30 \mathrm{~b} \pm 10.35$ \\
\hline
\end{tabular}

Data represent the mean \pm standard deviation of the triplicates. Means followed by different lower-case letters in the same line differ statistically by Tukey post-hoc test ( $\mathrm{p}<0.05)$. LB: Lyophilized bacaba; CB: Convective-dried bacaba; GAE: Gallic acid equivalent; ABTS: 2,2'-azino-bis (3-ethylbenzothiazoline) 6-sulfonic acid; DPPH: 2,2-diphenyl picrylhydrazyl. 
Sousa et al. (2018) with another variety of bacaba, whose values ranged from 18.77 to $77.99 \mu \mathrm{M}$ Trolox g ${ }^{-1}$. Rufino et al. (2010) found higher values with other Amazonian matrices, such as açaí $\left(64.5 \mu \mathrm{M}_{\text {Trolox g }}{ }^{-1} \mathrm{db}\right)$ and carnaúba $\left(16.4 \mu \mathrm{M} \mathrm{Trolox} \mathrm{g}^{-1} \mathrm{db}\right)$. The antioxidant ability is related to the high concentration of chemical groups such as the polyphenols present in the fruit, which act in the deactivation of free radicals (Brabo de Sousa et al., 2018).

The primary antioxidant capacity determined by the DPPH assay, expressed as IC50, showed averages of 1550.10 and $1757.3 \mathrm{~g}$ fruit $\mathrm{g}^{-1}$ for $\mathrm{LB}$ and $\mathrm{CB}$, respectively. For different genotypes of fan bacaba, Brabo de Sousa et al. (2018) reported values of 1510.48 to $6721.47 \mathrm{~g} \mathrm{DPPH} \mathrm{g}^{-1}$ fruit. Furthermore, Rezaire et al. (2014) evaluated açaí and patauá and found higher values of $2447 \mathrm{~g} \mathrm{DPPH} \mathrm{g}^{-1}$ fruit and $2292 \mathrm{~g} \mathrm{DPPH} \mathrm{g}^{-1}$ fruit, respectively. These comparative data are relevant as they indicate an inversely proportional relationship; the lower the IC50 value, the greater its radical scavenging capacity, meaning greater antioxidant capacity since a smaller amount of sample will be needed to act in the $50 \%$ reduction of the initial concentration of the DPPH radical (Brabo de Sousa et al., 2018).

The data presented in Table 1 indicate that the temperature of the convective drying, at $60^{\circ} \mathrm{C}$, acted considerably on the contents of bioactive compounds in the bacaba powder obtained by this method, reflecting their respective thermosensitivity. The high bioactive concentration was, however, maintained in the form obtained though freeze-drying (Méndez-Lagunas et al., 2017; Nemzer et al., 2018).

Other compounds can be found in dry products, these can be observed through chemical groups, spectral bands and specific vibration modes, as shown in Figure 1.

The FTIR spectra of LB and CB show absorption bands at similar frequencies, with small variations in intensity. Both have bands that varied between $3009-2850 \mathrm{~cm}^{-1}$ related to the methylene stretching vibration $\left(-\mathrm{CH}_{2}\right)$, with different intensities (Lei et al., 2018; Se et al., 2018).

Other bands that varied between $1758.5 \mathrm{~cm}^{-1}$ and $1746.1 \mathrm{~cm}^{-1}$ are present with strong intensity and are characteristic of the carbonyl group $(\mathrm{C}=\mathrm{O})$, methyl esters, ketones and aldehydes frequently found in materials that contain a long chain fatty acid profile and is related to the stretching elongation of the triacylglycerol ester bond $(-\mathrm{C}=\mathrm{O})$ and flexion of the aliphatic groups $\mathrm{CH}_{2}$ and $\mathrm{CH}_{3}(-\mathrm{C}-\mathrm{H})$ or the vibration of the amino groups $(\mathrm{N}=\mathrm{C})$, respectively (Santos et al., 2020).

Of note are the prominent bands at $1157 \mathrm{~cm}^{-1}$ and $1160 \mathrm{~cm}^{-1}$ in $\mathrm{LB}$ and $\mathrm{CB}$, respectively, which are characteristic of the carbonyl functional group (C-O), esters, ethers and carboxylic acids, are commonly named as a fingerprint region of the sample. Band absorption in this region is similar in both bacaba powders, with high intensity that may be linked to the high amount of oleic groups present in these samples. The last prominent bands are around $721.68 \mathrm{~cm}^{-1}$ and $720.1 \mathrm{~cm}^{-1}$ for LB and CB, respectively, and are associated with the presence of rocking vibration $\left(-\mathrm{CH}_{2}\right)$ $\mathrm{n}$ - (vibration outside the Cis plan), related to the aliphatic chain of fatty acids linked to the sequence of chains and aromatic rings of fatty acids and carbon-carbon bonds (Pinto et al., 2018; Se et al., 2018; Santos et al., 2020).

The morphological structures of each powder obtained by the different drying methods were analyzed (Figure 2). The morphology of the lyophilized bacaba pulp (Figure 2a) presented more conserved structures, with granules of irregular shape and surface, and bundles of fibers with small recesses wrapped in fibrillar conformations being distinguishable.

In Figure $2 \mathrm{~b}$ of the bacaba pulp obtained by convective drying, it was not possible to distinguish the structures, even in an enlarged form. The outer surface of the material had involutions and were similar to amorphous structures (Costa et al., 2019) with intense unstructured appearance and apparent destruction of plant parenchyma due to dehydrated material residues. These findings may be related to the drying temperature applied to the material during this method.

The structural and morphological differentiation between internal and external surfaces show that freeze-drying maintains the integrity of the material, with a surface and bundles of fibers being more apparent.
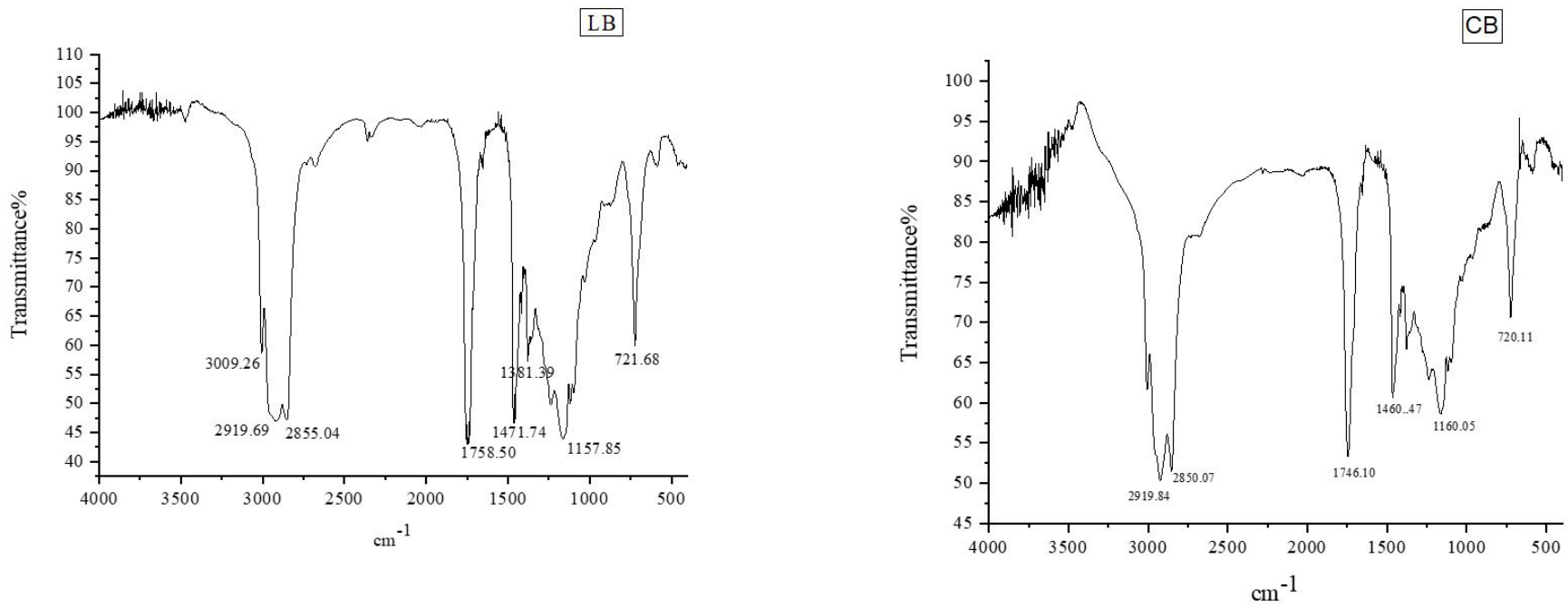

Figure 1. FTIR spectrum of the (a) lyophilized bacaba, LB, and (b) convective-dried bacaba, CB. 

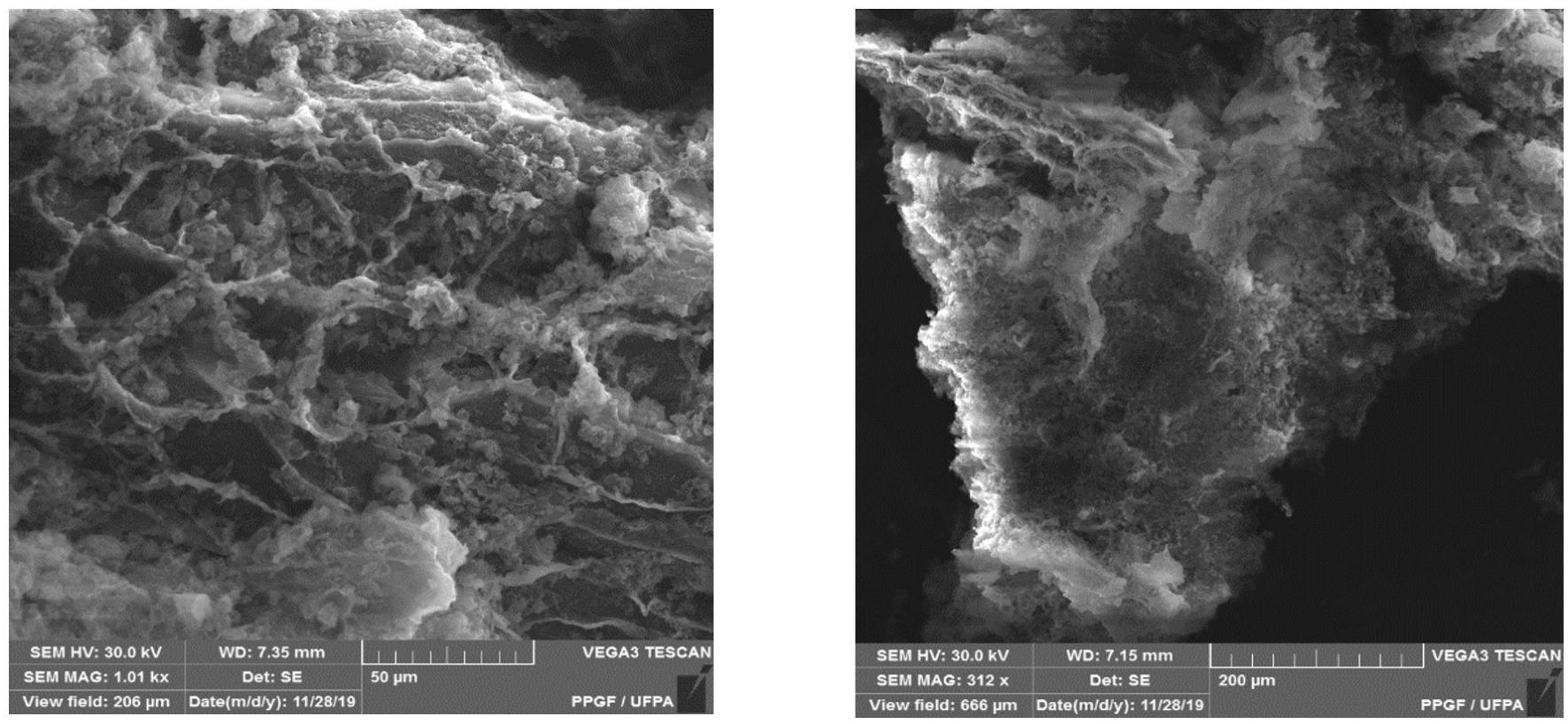

Figure 2. Scanning electronic micrography of (a) freeze-dried bacaba powder and (b) convective-dried bacaba powder under different degrees of magnification.

These data are related to the functional technological properties that may be present in this raw material. Spongy and fibrillar surfaces indicate its potential for use in the bakery and pasta segments in particular, as these food formulations require a matrix for absorbing and retaining materials like water, oil and other liquid compounds. This fact, combined with the results of the bioactive compounds, indicate a material with relevant nutritional, technological and functional action applicable to several industrial segments. Examples of these applications in the design of new products may be the inclusion of bacaba powder as a functional enrichment component in fronzens formulations, in yourtes as in research by Coskun \& Karabulut Dirican (2019), or as a base of probiotics similar to the food bases developed by Ribeiro et al. (2019).

Furthermore, in the morphology of the sample scanning zone (Figures 2a and 2b), there is the presence of material rich in carbon and other minerals, inferred through the EDS spectrum. It should be noted that elements in quantities less than $0.02 \%$ by mass cannot be detected. The elements hydrogen $(\mathrm{H})$, lithium ( $\mathrm{Li}$ ) and beryllium (Be) could not be detected by this technique. The main micronutrients in mass proportion are shown in Table 2.

With parameters and patterns for each mineral element taken from a database, the interpretation of EDS energies and the intensity of the X-ray beams produced over the area of the granules of LB and CB could be made.

The spectra of the micronutrients obtained by EDS from the SEM reveal carbon as the predominant element, with no difference between the samples. This major organic constituent is the basis of all plant compounds and human reactions, commonly linked to oxygen, hydrogen and other chemical compounds, and forming carbon dioxide present in the atmosphere, oceans, rivers and lakes.
Table 2. Elements (minerals) present in $\mathrm{CB}$ and $\mathrm{LB}$ powders.

\begin{tabular}{ccc}
\hline Elements & $\mathrm{CB} \%$ & $\mathrm{LB} \%$ \\
\hline $\mathrm{C}$ & 56.91 & 60.35 \\
$\mathrm{O}$ & 40.84 & 33.24 \\
$\mathrm{~S}$ & 0.17 & 0.51 \\
$\mathrm{Al}$ & - & 0.17 \\
$\mathrm{Cl}$ & 0.24 & 0.44 \\
$\mathrm{~K}$ & 1.45 & 4.37 \\
$\mathrm{Ca}$ & 0.09 & 0.40 \\
$\mathrm{Cu}$ & 0.06 & 0.31 \\
$\mathrm{Mn}$ & - & 0.05 \\
Total: & 100 & 100 \\
\hline
\end{tabular}

Carbon also forms the base or skeleton of the main energy sources, sugars, proteins and lipids, at the cellular level, specifically in mitochondrial ridges, producing energy for human reactions via the Krebs cycle.

The convective drying method led to a bacaba powder, which presented a higher oxygen content, making this form more prone to oxidation reactions (40.84\%), as well as lower sulfur and potassium contents, compared to the form obtained by freeze-drying.

The higher levels of sulfur and potassium in the composition of the LB form is justified, on the one hand, because sulfur is directly linked to the presence of sulfur proteins and participation in the production of enzymes and hormones, acting on the detoxification metabolism, in addition to being necessary for absorption of other minerals, such as selenium and zinc, which are vital elements for the immune system. On the other hand, potassium is related to the maintenance of muscle contraction processes with participation in the sodium and potassium "pump" in muscular energy systems. Thus, both these elements are crucial for maintaining health. 


\section{Conclusions}

Comparative data on the implementation of bacaba pulp drying techniques showed that the freeze-dried powder is a promising material for dietary applications. Its bioactive and antioxidant profile was superior to the powder obtained by convective drying. This behavior indicates the thermosensitivity of these compounds to the more drastic convective drying process. The patterns seen in the microscopy also confirm greater destruction of membrane structures in the matrix that had been submitted to convective drying. These data present the bacaba powder obtained by freeze-drying as a viable raw material for obtaining bacaba in the off-season, as well as for its bioactive antioxidants that could be applicable in several industrial segments for its functional benefits to human health.

\section{Acknowledgements}

The authors would like to thank FINEP (Financiadora de Estudos e Projetos) for the financial support and LABNANOAMAZON/UFPA for support through the SEM facilities used in the present work.

\section{References}

Aliakbarian, B., Casazza, A. A., \& Perego, P. (2011). Valorization of olive oil solid waste using high pressure-high temperature reactor. Food Chemistry, 128(3), 704-710. http://dx.doi.org/10.1016/j. foodchem.2011.03.092.

Association of Official Analytical Chemists - AOAC (2000). Official methods of analysis of of the Association of Official Analytical Chemists: method 920.153 (17th ed.). Washington: AOAC.

Becker, M. M., Mandaji, C. M., Catanante, G., Marty, J. L., \& Nunes, G. S. (2018). Mineral and bromatological assessment and determination of the antioxidant capacity and bioactive compounds in native Amazon fruits. Brazilian Journal of Food Technology, 21, 1-9. https:// doi.org/10.1590/1981-6723.02218.

Berto, A., Ribeiro, A. B., Sentandreu, E., de Souza, N. E., Mercadante, A. Z., Chisté, R. C., \& Fernandes, E. (2015). The seed of the Amazonian fruit Couepia bracteosa exhibits higher scavenging capacity against ROS and RNS than its shell and pulp extracts. Food \& Function, 6(9), 3081-3090. http://dx.doi.org/10.1039/C5FO00722D. PMid:26211429.

Brabo de Sousa, S. H., de Andrade Mattietto, R., Campos Chisté, R., \& Carvalho, A. V. (2018). Phenolic compounds are highly correlated to the antioxidant capacity of genotypes of Oenocarpus distichus Mart. fruits. Food Research International, 108, 405-412. http://dx.doi. org/10.1016/j.foodres.2018.03.056. PMid:29735073.

Britton, G., \& Khachik, F. (2009). Carotenoids in food. In G. Britton, S. Liaaen-Jensen \& H. Pfander (Eds.), Carotenoids: Nutrition and health (cap. 3, pp. 45-66). Switzerland: Birkhäuser Basel. http:// dx.doi.org/10.1007/978-3-7643-7501-0_3.

Carvalho, A. V., da Silveira, T. F., de Sousa, S. H. B., de Moraes, M. R., \& Godoy, H. T. (2016). Phenolic composition and antioxidant capacity of bacaba-de-leque (Oenocarpus distichus Mart.) genotypes. Journal of Food Composition and Analysis, 54, 1-9. http://dx.doi. org/10.1016/j.jfca.2016.09.013.

Coskun, F., \& Karabulut Dirican, L. (2019). Effects of pine honey on the physicochemical, microbiological and sensory properties of probiotic yoghurt. Food Science and Technology (Campinas), 39(Suppl. 2), 616-625. http://dx.doi.org/10.1590/fst.24818.
Costa, L. O., Lara, J. M. Jr, Costa, J. M. C., Afonso, M. R. A., Rodrigues, S., \& Wurlitzer, N. J. (2019). Stability and microstructure of powdered pulp of the Palmer mango obtained by the process of lyophilisation. Ciência Agronômica, 50(2), 251-258. http://dx.doi.org/10.5935/18066690.20190029.

Finco, F. D. B. A., Kloss, L., \& Graeve, L. (2016). Bacaba (Oenocarpus bacaba) phenolic extract induces apoptosis in the MCF-7 breast cancer cell line via the mitochondria-dependent pathway. NSF Journal, 5, 5-15. http://dx.doi.org/10.1016/j.nfs.2016.11.001.

Francis, F. J. (1982). Analysis of anthocyanins. In P. Markakis (Ed.), Anthocyanins as food colors (cap. 7, p. 182-208). New York: Academic Press. http://dx.doi.org/10.1016/B978-0-12-472550-8.50011-1.

Lauvai, J., Schumacher, M., Finco, A. F. D. B., \& Graeve, L. (2017). Bacaba phenolic extract attenuates adipogenesis by down-regulating PPAR $\gamma$ and C/EBPa in 3T3-L1 cells. NSF Journal, 9, 8-14. https:// doi.org/10.1016/j.nfs.2017.09.001.

Lei, M., Jiang, F. C., Cai, J., Hu, S., Zhou, R., Liu, G., Wang, Y. H., Wang, H. B., He, J. R., \& Xiong, X. G. (2018). Facile microencapsulation of olive oil in porous starch granules: fabrication, characterization, and oxidative stability. International Journal of Biological Macromolecules, 111, 755-761. http://dx.doi.org/10.1016/j.ijbiomac.2018.01.051. PMid:29329810.

Méndez-Lagunas, L., Rodriguez-Ramirez, J., Cruz-Gracida, M., Sandoval-Torres, S., \& Barriada-Bernal, G. (2017). Convective drying kinetics of strawberry (Fragaria ananassa): Effects on antioxidant activity, anthocyanins and total phenolic content. Food Chemistry, 230, 174-181. http://dx.doi.org/10.1016/j.foodchem.2017.03.010. PMid:28407898.

Morais, M. F., Santos, J. R. O., Santos, M. P., Santos, D. C., Costa, T. N., \& Lima, J. B. (2019). Modeling and thermodynamic properties of bacaba pulp drying. Revista Brasileira de Engenharia Agrícola e Ambiental, 23(9), 702-708. http://dx.doi.org/10.1590/1807-1929/ agriambi.v23n9p702-708.

Nascimento, R. A., Andrade, E. L., Santana, E. B., Ribeiro, N. F. P., Costa, C. M. L., \& Faria, L. J. G. (2019). Bacaba powder produced in spouted bed: an alternative source of bioactive compounds and energy food product. Brazilian Journal of Food Technology, 22, 1-15. http://dx.doi.org/10.1590/1981-6723.22918.

Nemzer, B., Vargas, L., Xia, X., Sintara, M., \& Feng, H. (2018). Phytochemical and physical properties of blueberries, tart cherries, strawberries, and cranberries as affected by diferente drying methods. Food Chemistry, 262, 242-250. http://dx.doi.org/10.1016/j. foodchem.2018.04.047. PMid:29751916.

Noronha Matos, K. A., Praia Lima, D., Pereira Barbosa, A. P., Zerlotti Mercadante, A., \& Campos Chisté, R. (2019). Peels of tucumã (Astrocaryum vulgare) and peach palm (Bactris gasipaes) are byproducts classified as very high carotenoid sources. Food Chemistry, 272, 216-221. http://dx.doi.org/10.1016/j.foodchem.2018.08.053. PMid:30309535.

Pinto, R. H. H., Sena, C., Santos, O. V., Da Costa, W. A., Rodrigues, A. M. C., \& Carvalho, R. N. Jr. (2018). Extraction of bacaba (Oenocarpus bacaba) oil with supercritical $\mathrm{CO}_{2}$ : global yield isotherms, fatty acid compo $\neg$ sition, functional quality, oxidative stability, spectroscopic profile and antioxidant activity. Grasas y Aceites, 69(2), 1-8. http:// dx.doi.org/10.3989/gya.0883171.

Re, R., Pellegrini, N., Proteggente, A., Pannala, A., Yang, M., \& RiceEvans, C. (1999). Antioxidant activity applying an improved ABTS radical cation decolorization assay. Free Radical Biology \& Medicine, 26(9-10), 1231-1237. http://dx.doi.org/10.1016/S0891-5849(98)003153. PMid:10381194. 
Rezaire, A., Robinson, C., Bereau, D., Verbaere, A., Sommerer, N., Khan, M. K., Durand, P., Prost, E., \& Fils-Lycaon, B. (2014). Amazonian palm Oenocarpus bataua ("patawa"): Chemical and biological antioxidant activity - phytochemical composition. Food Chemistry, 149, 62-70. http://dx.doi.org/10.1016/j.foodchem.2013.10.077. PMid:24295677.

Ribeiro, A. S., Silva, M. N., Tagliapietra, B. L., Brum Júnior, B. S., Ugalde, M. L., \& Richards, N. S. P. S. (2019). Development of symbiotic yoghurt and biological evaluation (New Zealand White Rabbits) of its functional properties. Food Science and Technology (Campinas), 39(Suppl. 2), 418-425. http://dx.doi.org/10.1590/fst.20618.

Rufino, M. S. M., Alves, R. E., de Brito, E. S., Pérez-Jiménez, J., SauraCalixto, F., \& Mancini-Filho, J. (2010). Bioactive compounds and antioxidant capacities of 18 non-traditional tropical fruits from Brazil. Food Chemistry, 121(4), 996-1002. http://dx.doi.org/10.1016/j. foodchem.2010.01.037.

Santos, M. F., Mamede, R. V., Rufino, M. S., Brito, E. S., \& Alves, R. E. (2015). Amazonian native palm fruits as sources of antioxidant bioactive compounds. Antioxidants, 4(3), 591-602. http://dx.doi. org/10.3390/antiox4030591. PMid:26783846.

Santos, O. V., Gonçalves, B. S., Macêdo, C. S., Conceição, L. R. V., Costa, C. E. F., Monteiro Júnior, O. V., Souza, A. L. G., \& Lannes, S. S. C.
(2020). Evaluation of quality parameters and chromatographic, spectroscopic, and thermogravimetric profile of Patauá oil (Oenocarpus bataua). Food Science and Technology (Campinas), 40(Suppl. 1), 76-82. http://dx.doi.org/10.1590/fst.01619.

Se, K. W., Ghoshal, S. K., Wahab, R. A., Ibrahim, R. K. R., \& Lani, M. N. (2018). A simple approach for rapid detection and quantification of adulterants in stingless bees (Heterotrigona itama) honey. Food Research International, 105, 453-460. http://dx.doi.org/10.1016/j. foodres.2017.11.012. PMid:29433236.

Silva, A. K. N., Beckman, J. C., Rodrigues, A. M. C., \& Silva, L. H. M. (2017). Avaliação da composição nutricional e capacidade antioxidante de compostos bioativos da polpa de açaí. Revista brasileira de Tecnologia Agroindustrial, 11(1), 2205-2216. http:// dx.doi.org/10.3895/rbta.v11n1.2829.

Statsoft. (2000). Statistica: data analysis software system (Version 7.0). Tulsa: Statsoft.

Tepe, B., Daferera, D., Tepe, A. S., Polissiou, M., \& Sokmen, A. (2007). Antioxidant activity of the essential oil and various extracts of Nepeta flavida Hub.-Mor. from Turkey. Food Chemistry, 103(4), 1358-1364. http://dx.doi.org/10.1016/j.foodchem.2006.10.049. 